\title{
Politics Turns Moral Foundations Into Consequences of Intergroup Attitudes
}

\author{
Márton Hadarics (10 and Anna Kende \\ Department of Social Psychology, ELTE Eötvös Loránd University, Budapest, Hungary
}

\begin{abstract}
Applying a longitudinal design, we tested the directions of the relationships between moral foundations and attitudes toward Muslim immigrants. The study was conducted during the official campaign period of the Hungarian parliamentary elections in 2018 . It was found that moral foundations are consequences of intergroup attitudes. Latent change modeling showed that while individualizing foundations were independent of anti-Muslim attitudes, longitudinal change in binding foundations was predicted by prior anti-Muslim attitudes, but not the other way around. Furthermore, this relationship was moderated by exposure to the anti-Muslim and anti-immigration campaigns led by the government. These results suggest that people are motivated to harmonize their moral concerns with their prior social beliefs, and they actively utilize available political messages in this process.
\end{abstract}

Keywords: moral foundations, prejudice, political communication, campaign, Muslims

The European Refugee Crisis that started in 2015 has undoubtedly had an effect on the political landscape of Europe. One of the most important of these effects was that many anti-immigrant populist parties, like the AfD (Alternative für Deutschland) in Germany, the Lega Nord in Italy, or the FPÖ (Freiheitliche Partei Österreichs) in Austria became stronger, but the biggest winner of this phenomenon was Viktor Orbán's Fidesz party in Hungary, which won the parliamentary election in 2018 with a constitutional majority for the third time in a row. Fidesz has pursued an extremely harsh anti-immigrant and antiMuslim agenda since 2015, which may be the main reason for its domestic political success (Bíró-Nagy, 2018).

In this paper, we argue that such an intense negative anti-Muslim campaign affects people's moral values, but this effect depends on prior intergroup attitudes. Building upon moral foundations theory (MFT; Haidt \& Joseph, 2004) and research on motivated moral judgment (e.g., Eriksson et al., 2019; Voelkel \& Brandt, 2019), we demonstrate through the example of the Hungarian parliamentary election campaign in 2018 that moral foundations are not just foundations but also consequences of intergroup attitudes. At least occasionally, people tend to modify their moral values to be in line with their other social beliefs (like intergroup attitudes), and while doing this, they rely on available morally relevant information. Political campaigns can be unlimited resources of this kind of information, therefore being exposed to them can facilitate and direct how moral foundations become moral consequences.

\section{Moral Values and Intergroup Attitudes}

There has been a growing interest of research about the moral aspects of intergroup relations and attitudes (e.g., Ellemers, 2017; Halevy et al., 2015; Waytz \& Young, 2018), and beyond doubt, one of the most important theoretical framework contributing to this literature is moral foundations theory (MFT; Haidt \& Joseph, 2004; Graham et al., 2013, 2018). According to MFT, moral judgments stem from intuitive, emotionally driven processes that are based on an evolutionary designed and culturally finetuned psychological system. The main function of this system is to direct moral intuitions in a way that they prevent selfish behaviors and therefore ensure cooperation between individuals. This goal is achieved by emphasizing certain moral foundations in these intuitive processes.

Moral foundations represent different moral concerns serving as personal criteria in decisions about what is right and wrong. The theory describes five such foundations that are often categorized into two more extensive clusters of individualizing and binding foundations (e.g., Graham et al., 2011, 2013). Individualizing foundations (including care and fairness) protect the community from individual 
selfishness by direct disapproval and prohibition of doing harm to others, and by making people respect the rights of other individuals. Binding foundations (including loyalty, authority, and purity) achieve this by binding people to cohesive groups and institutions, and by creating welldefined roles within these groups and their institutional systems.

The main goal of the MFT was to provide an explanation for the essential moral value differences between social groups such as conservatives and liberals or members of collectivist and individualist cultures (for review, see Graham et al., 2013). However, there has lately been a rapidly growing interest in how moral intuition, an immediate and non-argumentative form of moral judgment based on these two sets of moral foundations (Haidt, 2012) can explain intergroup attitudes and preferences. So far, studies have shown that individualizing foundations are related to more positive attitudes and binding foundations to more negative attitudes toward outgroups like Muslims (Hadarics \& Kende, 2018a; Kugler et al., 2014; Van de Vyver et al., 2016), immigrants (Baldner \& Pierro, 2019; Hadarics \& Kende, 2017; Van de Vyver et al., 2016), sexual outgroups (Barnett et al., 2018; Monroe \& Plant, 2019), poor people (Low \& Wui, 2016), beggers (Nilsson et al., 2016), or foreigners (Nilsson et al., 2020; Smith et al., 2014). Furthermore, moral foundations were also found to be related to more generalized dimensions of prejudice, like attitudes toward "dangerous," "derogated," and "dissident" groups (Forsberg et al., 2019; Hadarics \& Kende, 2018b).

There are several alternative explanations for these differences regarding the relationship between moral foundations and outgroup attitudes. These differences can be explained by group-based exclusion and inclusion as consequences of individualizing and binding foundations. People with stronger binding foundations are mainly concerned with the well-being of their ingroup and are less sensitive to the needs and problems of outgroup members, whereas those with stronger individualizing foundations do not make this strong group-based distinction and think about others in a more egalitarian way. Seemingly, they consider basic moral guidelines in a more universalistic manner (e.g., Hadarics \& Kende, 2018a; Low \& Wui, 2016; Nilsson et al., 2016). Others highlight that the cohesion of the ingroup and adherence to its norms are of vital importance for people with strong binding foundations, that is why culturally different or non-conventional outgroups may be perceived as a potential source of threat to this cohesion and to the well-being of the ingroup (e.g., Barnett et al., 2018; Hadarics \& Kende, 2017, 2018b; Low \& Wui, 2016; Van de Vyver et al., 2016).

Although MFT acknowledges that contextual factors (like experimental manipulations) can temporarily modify one's moral foundations (Haidt et al., 2009), the theory describes these foundations as stable personal dispositions. Accordingly, the above-cited explanations for the relationship between moral foundations and intergroup attitudes also consider moral foundations as actual foundations or causes of intergroup attitudes.

\section{Moral Foundations as Motivated Consequences of Social Beliefs}

Recently, multiple lines of research have questioned that moral foundations can be considered exclusively as actual foundations (or causes) of more specific social beliefs and started to emphasize that people can shift their moral values (measured as moral foundations) in order to satisfy temporary motivations. Experimental research indicates that the need for group-justification is such a motivational factor. People tend to cultivate moral values that they think are cultivated by their ingroup and downplay the relevance of moral values that they think are cultivated by an antagonistic outgroup (Ciuk, 2018). They also tend to degrade moral values that were violated by their ingroup but upgrade those that were violated by an antagonistic outgroup or outgroup member (Eriksson et al., 2019; Walter \& Redlawsk, 2019), and it seems that the personal relevance of different moral values is influenced also by whether the target of a morally relevant act is a member of the ingroup or an antagonistic outgroup (Eriksson et al., 2019; Voelkel \& Brandt, 2019).

Another line of research, relying on longitudinal crosslagged panel studies (Hatemi et al., 2019; Smith et al., 2017), show that in the relationship between moral foundations and ideological preferences, ideology determines moral foundations much more than the other way around. These studies also reported weak test-retest stability of moral foundations scores and suggested that moral foundations are context-dependent states rather than dispositional traits, and as such, they are posterior moral justifications of ideological preferences. Finally, the third line of research investigated the role of intergroup threat. It was found that binding morality intensifies at the expense of individualizing morality if the ingroup is perceived to be threatened by an outgroup (Van de Vyver et al., 2016; Wright \& Baril, 2013). These results were explained by the idea that binding foundations can be effective tools for restoring or enhancing group-based security.

Taken together these results indicate that moral values and priorities can change in line with our prior outgroup attitudes, and also with the way we precisely perceive a particular outgroup. If we do not like an outgroup, and we perceive it as violating certain moral values, we can be motivated to overemphasize those values to rationalize our initial negative feelings. Nonetheless, if we do not have 
personal contact with the outgroup, the way we perceive it can heavily depend on indirect sources like political communication and media framing (Semetko, 2007; Valentino \& Nardis, 2013).

\section{The Hungarian Election Campaign of 2018 as the Moral Framing of Immigration}

The issue of immigration has been among the most emphasized political topics in Hungary since the beginning of the European Refugee Crisis started in 2015 (Bernáth \& Messing, 2015; Kende \& Krekó, 2020), and it was in the center of the election campaign led by the Fidesz, the re-elected right-wing government party (Bajomi-Lázár, 2019; Tóth et al., 2019). The main message of the campaign was that mass-immigration from Muslim countries is the most severe threat to Hungary and Europe. According to the narrative of the Fidesz campaign, immigration from Muslim countries is planned and organized by George Soros, a Hungarian-American billionaire with the help of NGOs and Hungarian and European liberal political actors whom he personally financed. The explicit message of the campaign was that their plan was to disintegrate traditionally Christian European nation-states by arranging the immigration of a great number of Muslim people (Bajomi-Lázár, 2019; Bíró-Nagy, 2018).

Within this campaign, values directly reflecting binding moral foundations were strongly emphasized. According to the narrative of the Hungarian government, immigration from Muslim countries destroys the cohesiveness of European nations and their cultural heritage, which fits in with the notion of MFT emphasizing that the primary use of binding foundations is the maintenance of ingroup cohesion (Graham et al., 2013). Furthermore, more specific binding values were reflected in the cornerstones of the Fidesz-campaign, like the religious and cultural conflict between Christianity and Islam (sanctity), ${ }^{1}$ the symbolic threat represented by Muslim immigrants to the Hungarian culture and lifestyle (authority/tradition), ${ }^{2}$ and the disloyalty of liberal and left-wing politicians who assist the immigration process (ingroup loyalty). ${ }^{3}$

Another characteristic of this campaign was that the opposition parties neglected the issue of immigration in their own campaign and focused on government corruption, and the state of democratic procedures and institutions (Bíró-Nagy, 2018; Tóth et al., 2019). Because of the thematic mismatch of the campaigns, and because Fidesz had significantly larger access to national media, than the opposition (i.e., all public TV and radio channels and most commercial TV and radio channels are under the direct control of the government; Bátorfy, 2017; Mérték Media Monitor, 2019), voters were exposed predominantly to the narrative and moral framing of Fidesz on immigration from Muslim countries, and not alternative frames of this issue.

\section{Hypotheses and Research Questions}

In our longitudinal research, we tried to reveal how exposure to the intense anti-Muslim campaign during the 2018 Hungarian parliamentary elections affected people's moral values. We assumed that people can shift their moral values based on their initial intergroup attitudes, and this shift is influenced by how the media frames the behavior of the outgroup. More precisely, we hypothesized that people with a negative initial attitude toward Muslim immigrants will increase their binding morality, and this relationship will be stronger in case of intense exposure to the campaign since this campaign heavily emphasized how Muslim immigrants threaten and violate binding moral aspects. As it seems that in the case of perceived intergroup threat binding morality intensifies at the expense of individualizing morality, we tested also whether the same moderation is true in the case of individualizing morality.

Nevertheless, we did not rule out the possibility that moral foundations can also work as actual foundations of intergroup attitudes, consequently, we checked the temporal relationship between moral foundations and outgroup attitudes in both directions. Lastly, we also hypothesized that if there is a longitudinal relationship between moral foundations (Time 1) and outgroup attitude (Time 2), campaign exposure would moderate that relationship too, and this relationship would be stronger for those who followed the campaign more closely. We hypothesized this because political communication, due to its agenda-setting function, can direct voters' attention toward specific outgroups, like Muslim people in this case, and make them targets of derogation.

\footnotetext{
As an institutional example for emphasizing this conflict, the position of the Deputy State Secretary for the Aid of Persecuted Christians was founded in 2016.

${ }^{2}$ As Viktor Orbán (2018) said in his campaign opening speech about Muslim immigration into Europe: "If things continue like this, our culture, our identity, and our nations as we know them will cease to exist. Our worst nightmares will have become reality."

${ }^{3}$ As one of the most infamous examples, a campaign billboard displayed all opposition leaders together with George Soros with pincers in their hands with the following subtitle: "They would tear down the border barrier together." The billboard referred to the physical border barrier that was installed on the southern border of Hungary in 2015 to prevent refugees from entering the country.
} 


\section{The Study}

To test these hypotheses, we conducted a two-wave longitudinal survey study during the official campaign period of the Hungarian parliamentary elections held in the spring of 2018. This design enabled us to test the temporal directions between moral foundations and intergroup attitudes and to test which of these variables is the longitudinal antecedent of a change in the other. This longitudinal design also made it possible to check the moderating role of campaign exposure between the two waves of data collection. The two waves were administered in the first and the last week of the official campaign period of the 2018 parliamentary elections, which took place between February 17 and April 8. The administered questionnaires were part of an omnibus survey that we conducted online using the Qualtrics software. We report all measures for variables related to the research question.

\section{Participants}

Our participants were members of the majority Hungarian population who were recruited by a professional public opinion research company. Originally, the sample was demographically similar to the population of Hungary in terms of gender, age, level of education, and type of residence $(N=555)$. However, the final sample can no longer be considered fully representative because of the dropouts between the two data collection rounds. We analyzed the data only from those respondents who completed both rounds since campaign exposure was measured only in the second round. Our final sample consisted of 265 respondents, who were all members of the Hungarian majority population (131 women, $M_{\mathrm{age}}=50.05 ; S D_{\mathrm{age}}=$ 14.50). In terms of their educational background, $36.2 \%$ had a college or university degree, $42.3 \%$ had a high-school diploma, $17.4 \%$ completed vocational school, and $2.3 \%$ had primary education or less.

\section{Measures}

\section{Moral Foundations}

For measuring moral foundations, we used a shortened Hungarian version of the Moral Foundation Questionnaire (MFQ; Graham et al., 2011) developed by Hadarics and Kende (2017). This Hungarian version was designed to measure individualizing and binding moral foundations since the original five-factor structure of the MFQ could not be replicated in the Hungarian context (Hadarics \& Kende, 2017). It contains 10 items from the original 15 moral relevance items, 4 measuring individualizing morality, and 6 measuring binding morality (2 for each original foundation). Previous studies applying this version of the MFQ found the expected relationships between the two dimensions of moral foundations and other variables like right-wing authoritarianism, social dominance orientation, group-based moral exclusion, or prejudice against different outgroups (Hadarics \& Kende, 2017, 2018a, 2018b). Respondents indicated their answers according to the original 6-point scale of the MFQ $(1=$ not at all relevant; $6=$ extremely relevant). Moral foundations were measured in both data collection waves (sample items: "Whether or not someone conformed to the traditions of society"; "Whether or not someone was denied his or her rights").

\section{Intergroup Attitude (Attitude Toward Muslim Immigrants)}

Respondents' attitudes toward Muslim immigrants were measured with three indicators in both data collection rounds, a feeling thermometer item and two standard social distance items from the Eurobarometer (2015) item pool. We chose these indicators because they tap into a general evaluation of the attitude object, and they do not measure specific beliefs about Muslim immigrants what could also have been parts of the election campaign messages. The feeling thermometer item asked respondents to indicate on a 10-point scale how dislikable or likable they find typical Muslim immigrants $(1=$ dislikable $; 10=$ likable $)$, while in the case of the social distance items respondents indicated on a 10-point scale how comfortable they would feel if they had a Muslim immigrant colleague or one of their children had a Muslim immigrant partner $(1=$ not at all comfortable; $10=$ totally comfortable). Since our hypotheses were related to prejudice rather than a positive attitude, we reversed these scores to indicate the individual level of a negative attitude.

\section{Campaign Exposure}

We measured our respondents' exposure to the parliamentary election campaign only in the second data collection round by asking how closely they followed political events and the election campaign in the campaign period. They indicated their answer on a 7 -point scale $(1=$ not at all; $7=$ very (losely).

\section{Control Variables}

When testing the longitudinal relationships between moral foundations and anti-Muslim prejudice, we controlled for the effect of respondents' gender $(1=$ man; $2=$ woman $)$, age, educational level $(1=$ no more than primary education; $4=$ university/college degree $)$, subjective income status $(1=$ significantly below average; 5 = significantly above average), and left-right ideological preferences $(1=$ left; $7=$ right $)$.

\section{Data Analysis and Results}

Our research data is available in ESM 2. The amount of missing data was low (2.14\%) in the dataset and was handled with full information maximum likelihood estimation in each analysis. To test how temporal changes in 
Table 1. Model fits of measurement invariance models

\begin{tabular}{|c|c|c|c|c|c|c|c|}
\hline Model & $\chi^{2}$ & $d f$ & RMSEA & SRMR & $\mathrm{CFI}$ & Gamma hat & Mc \\
\hline 13 items - Construct invariance & 516.71 & 271 & .058 & .054 & .945 & .934 & .628 \\
\hline 13 items - Metric invariance & 531.73 & 284 & .057 & .060 & .944 & .934 & .626 \\
\hline 13 items - Scalar invariance & 568.06 & 297 & .059 & .064 & .939 & .926 & .599 \\
\hline 12 items - Construct invariance & 383.38 & 225 & .052 & .051 & .961 & .952 & .741 \\
\hline 12 items - Metric invariance & 397.27 & 237 & .051 & .058 & .961 & .951 & .738 \\
\hline 12 items - Scalar invariance & 418.02 & 249 & .051 & .060 & .959 & .949 & .726 \\
\hline
\end{tabular}

Note. $\chi^{2}=$ Chi-Square; $d f=$ Degree of Freedom; RMSEA = Root Mean Square Error of Approximation; SRMR = Standardized Root Mean Square Residual; $\mathrm{Mc}=$ McDonald's Non-Centrality Indices.

moral foundations are predicted by intergroup attitude, and vice versa, and whether these longitudinal relationships are moderated by campaign exposure, we applied latent change modeling (LCM; McArdle, 2009). This technique enabled us to test how temporal changes in multiple variables from Time 1 (T1) to Time 2 (T2) correlate with predictor variables measured at $\mathrm{T} 1$, and with additional control variables. This technique investigates individual changes, while former longitudinal studies involving moral foundations (Hatemi et al., 2019; Smith et al., 2017) applied a cross-lagged panel design that is suitable to test changes in rank-order positions only, which is not an ideal tool to test intraindividual changes.

In case of multiple indicator variables (e.g., multiple item scales), an essential requirement of the LCM technique is the longitudinal measurement invariance of these variables, since it must be guaranteed that the so-called latent change (or true change) variables in these models are not confounded by measurement error due to measurement non-invariance across the measurement occasions. Former longitudinal studies involving moral foundations (Hatemi et al., 2019; Smith et al., 2017) did not check the measurement invariance of the MFQ so it cannot be ruled out that a longitudinal change in moral foundations was due to measurement inconsistencies in those studies. We checked the measurement invariance of the intergroup attitude and moral foundations items by confirmatory factor analysis. All analyses were conducted with the MPlus 8 software (Muthén \& Muthén, 1998-2017).

To check longitudinal measurement invariance, we set up a model with six latent factors (Binding foundations at $\mathrm{T} 1$ and $\mathrm{T} 2$, Individualizing foundations at $\mathrm{T} 1$ and $\mathrm{T} 2$, and Intergroup attitudes at $\mathrm{T} 1$ and $\mathrm{T} 2$ ), where all factor loadings and item intercepts were let vary freely. Retest correlations between the corresponding items between $\mathrm{T} 1$ and $\mathrm{T} 2$ were imposed, as in all subsequent models. This model showed an acceptable fit, suggesting an adequate factor structure that is longitudinally invariant (see all model fits in Table 1). Factor loadings were adequate, ranging between .61 and
.93. For subsequent nested model comparisons, we applied $\Delta \chi^{2}$ tests and checked also changes in McDonald's (1989) Non-centrality Indices $(\mathrm{Mc})$ with a $\Delta \mathrm{Mc}<.02$ cut-off criteria for invariance, since $\Delta \chi^{2}$ tests can be affected by sample size and model complexity (Newsom, 2015).

Using the construct invariance model as a comparative baseline, we could reveal also metric invariance by constraining factor loadings as being equal across time $\left(\Delta \mathrm{Mc}=.002 ; \Delta \chi^{2}=15.02 ; \Delta d f=13 ; p=.306\right)$, but not scalar invariance by constraining item intercepts as being equal across time, and comparing this model to the metric invariance model $\left(\Delta \mathrm{Mc}=.027 ; \Delta \chi^{2}=36.33 ; \Delta d f=13 ; p<.001\right)$. Subsequent single-item analysis showed that scalar invariance could be achieved by removing one specific item of the binding foundations subscale ("Whether or not someone did something disgusting") from the model, but not by removing any other items. ${ }^{4}$ After removing this item, we checked longitudinal construct, metric, and scalar invariance again, and found that the fit of the construct invariance model improved further (see Table 1). Factor loadings were adequate ranging between .63-.93, and by subsequent modeling we found both metric $(\Delta \mathrm{Mc}=.003$; $\left.\Delta \chi^{2}=13.89 ; \Delta d f=12 ; p=.308\right)$ and scalar invariance $\left(\Delta \mathrm{Mc}=.012 ; \Delta \chi^{2}=20.75 ; \Delta d f=12 ; p=.054\right)$ Fit indices of these models are shown also in Table 1.

After testing that by dropping one item our multi-item measures had the same measurement properties across time, we conducted the LCM procedure. The essence of this technique is to split the variance of variables measured at $\mathrm{T} 2$ into two parts. A part that can be fully explained by the same construct measured at $\mathrm{T} 1$, what is achieved by setting an autoregressive path from $\mathrm{T} 1$ to $\mathrm{T} 2$ and constraining it to the value of 1 . The other part of the $\mathrm{T} 2$ variance represents the true change in the given construct between $\mathrm{T} 1$ and $\mathrm{T} 2$, and it is specified by a latent variable which is also connected to the $\mathrm{T} 2$ variable by a path constrained to the value of 1 . Since the T2 variable does not allow to have an error term, its variance is fully explained by the $\mathrm{T} 1$ value of the same construct and the latent variable,

\footnotetext{
${ }^{4}$ The non-invariant intercept of this item was lower at T2 (4.37; SE $\left.=.07 ; p<.001\right)$ than at T1 $(4.69 ;$ SE $=.07 ; p<.001)$, which indicates that respondents were tended to give lower scores for this item at T2 regardless of their individual standing on the latent construct of binding foundations.
} 


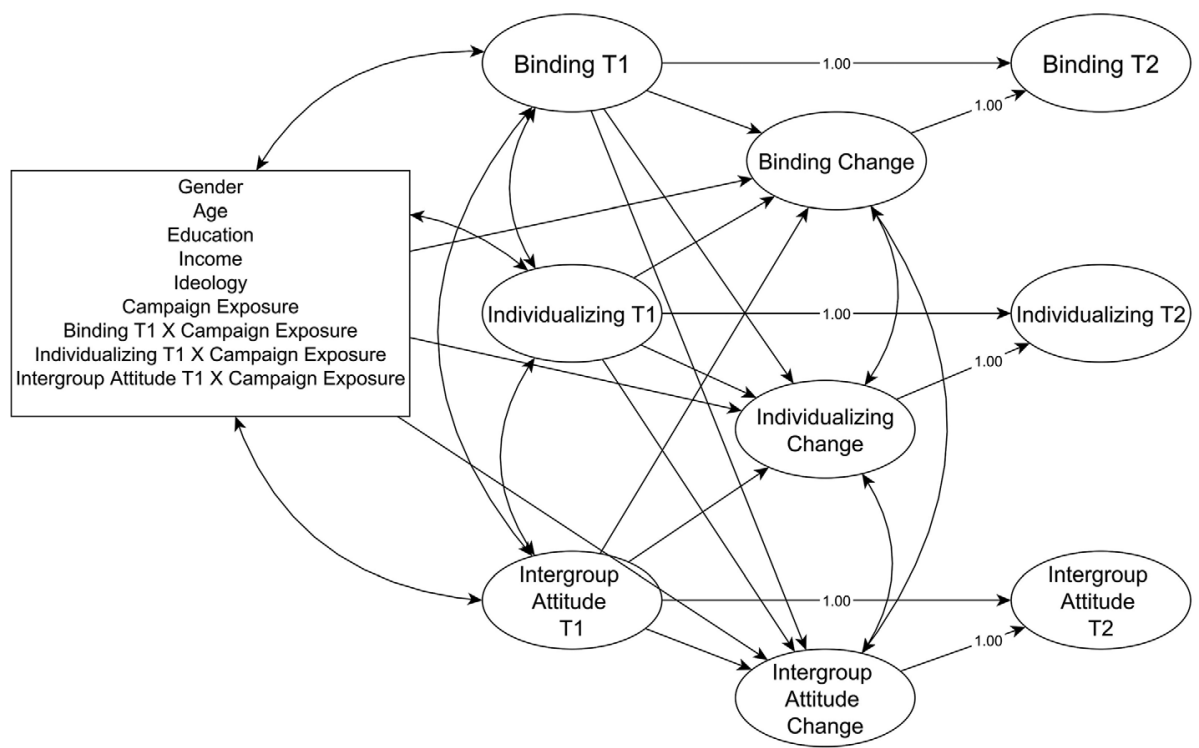

Figure 1. Structural outline of the LCM model.

which in this way represents the true individual change in the measured construct across time (T2 - T1). We also specified a freely estimated path between the $\mathrm{T} 1$ variables and the latent change variables of the same constructs, which is the so-called self-feedback path, and shows how accurately the $\mathrm{T} 1$ value of a construct predicts its temporal change (Newsom, 2015).

In our modeling procedure, we set up such a latent change structure for binding and individualizing foundations, and intergroup attitude alike in one model. Each T1 and $\mathrm{T} 2$ variable of these constructs was specified as a latent variable built up from its corresponding questionnaire items in order to eliminate measurement error. Retest correlations and equality constraints between the corresponding items between $\mathrm{T} 1$ and $\mathrm{T} 2$ were imposed, just like in the scalar invariance model. We also let the latent change variables correlate with each other, and we applied each $\mathrm{T} 1$ variable as a predictor for each latent change variable. This allowed us to test the longitudinal relationships between the two kinds of moral foundations and intergroup attitude. Furthermore, we also used campaign exposure and the control vari- ables as predictors for the latent change variables. Campaign exposure and the control variables were centered before setting up the model. Finally, an interaction term between campaign exposure and intergroup attitudes at $\mathrm{T} 1$ was also specified for predicting change in the two kinds of moral foundations, and two other interactions between campaign exposure and the two sorts of moral foundations at $\mathrm{T} 1$ for predicting the change in intergroup attitude. A structural outline of the LCM model is shown in Figure 1.

Correlations between the latent and observed variables are shown in Table 2, and regression coefficients of the latent change model in Table $3{ }^{5,6}$ Since the Mplus software (or any other software that we know of) is not capable of computing model fit indices for models with latent variable interactions (which were essential to incorporate into our model to test our hypotheses about the moderating role of campaign exposure), we report model fit statistics of the same model without latent variable interactions. These indices indicate that our model showed a good fit to the data $\left(\chi^{2}=533.58 ; d f=354 ;\right.$ RMSEA $=.044$; SRMR $=$ .052; $\mathrm{CFI}=.957){ }^{7}$

\footnotetext{
${ }^{5}$ Beyond the retest correlations between T1 and T2 latent variables, we provide additional data in Electronic Supplementary Material (ESM 1) indicating that there is an actual intraindividual longitudinal change in the three tested variables (binding and individualizing foundations, and intergroup attitude) that can be predicted by other variables. These results show that the absolute change (from T1 to T2) of each moral foundation and intergroup attitude item is significantly different from zero (see Table E1), which means that there is an intraindividual longitudinal change in the responses for these items. This is also supported by the fact that the estimated variance of each latent change variable is significantly different from zero (see Table E2) (Table E2 shows also that the estimated means of the latent change variables do not differ from zero, but this indicates only that we cannot identify a specific direction of overall change within the sample since different individuals' scores change in different directions). Furthermore, we also found that raw change scores of items measuring the same construct significantly (and substantially) correlate with each other (Table E3), which indicates that items measuring the same construct changed in the same direction.

${ }^{6}$ Regression coefficients of the model without control variables can be found in ESM 1 (Table E5).

7 In ESM 1 (Table E4), we also report the fit statistics of the same model without control variables, and we also report fit statistics of single latent change variable models. These models explain latent changes in binding and individualizing foundations, and intergroup attitudes separately with the same predictors as the final full model. Each model shows an acceptable fit indicating that the main parts of the final model are specified adequately.
} 
Table 2. Correlations between latent variables and control variables, and their descriptive statistics

\begin{tabular}{|c|c|c|c|c|c|c|c|c|c|c|c|c|}
\hline & 1. & 2. & 3. & 4. & 5. & 6. & 7. & 8. & 9. & 10. & 11. & 12. \\
\hline 1. Binding foundations $\mathrm{T} 1$ & 1.00 & $.72 * \star \star$ & $.17 *$ & $.55^{\star \star \star}$ & $.37 * * *$ & $.20 * \star$ & .05 & $.16^{*}$ & .09 & .00 & -.05 & .12 \\
\hline 2. Individualizing foundations T1 & & 1.00 & $-.23^{\star \star}$ & $.33^{* * *}$ & $.51 * \star \star$ & $-.16^{\star}$ & $.24 * * \star$ & .11 & $.12^{\star}$ & $.14^{\star}$ & .03 & -.07 \\
\hline 3. Intergroup attitude T1 & & & 1.00 & $.29 * \star$ & -.06 & $.85 * \star \star$ & $-.19 \star \star$ & .11 & -.05 & $-.34 * \star \star$ & $-.33 * \star \star$ & 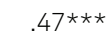 \\
\hline 4. Binding foundations $\mathrm{T} 2$ & & & & 1.00 & $.85^{\star \star \star}$ & $.28 * \star \star$ & .11 & $.14^{\star}$ & .08 & -.06 & $-.19 \star \star$ & $.19 *$ \\
\hline 5. Individualizing foundations $\mathrm{T} 2$ & & & & & 1.00 & -.04 & $.26 * \star \star$ & .13 & .11 & .05 & -.09 & -.03 \\
\hline 6. Intergroup attitude T2 & & & & & & 1.00 & $-.15^{\star}$ & $.13^{*}$ & -.08 & $-.24^{\star \star \star}$ & 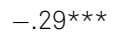 & $.42^{\star \star \star}$ \\
\hline 7. Campaign exposure & & & & & & & 1.00 & $-.12^{\star}$ & $.35 * \star *$ & $.19 * \star$ & .03 & -.05 \\
\hline 8. Gender & & & & & & & & 1.00 & -.08 & -.12 & $-.20 \star \star$ & .06 \\
\hline 9. Age & & & & & & & & & 1.00 & .12 & 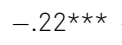 & -.08 \\
\hline 10. Education & & & & & & & & & & 1.00 & $.33^{* \star *}$ & $-.22 \star \star$ \\
\hline 11. Income & & & & & & & & & & & 1.00 & $-.13^{\star}$ \\
\hline 12. Ideology & & & & & & & & & & & & 1.00 \\
\hline Mean & 0.00 & 0.00 & 0.00 & -.0 .03 & -0.02 & 0.04 & 4.64 & $N=265$ & 50.25 & 3.15 & 2.48 & 4.24 \\
\hline$S D$ & .87 & .81 & 2.04 & .86 & .80 & 2.25 & 1.90 & (131 women) & 14.45 & .77 & 1.08 & 1.72 \\
\hline
\end{tabular}

Note. ${ }^{*} p<.05 ;{ }^{* \star} p<.01 ;{ }^{* *} p<.001$.

Results of the model showed that change in individualizing foundations was related to the change in binding foundations ( $\operatorname{cov}=.43 ; S E=.09 ; p<.001)$ but not to the change in intergroup attitudes ( $\operatorname{cov}=-.01 ; S E=.07 ; p=$ .854 ), while this latter was unrelated to the change in binding foundations ( $\operatorname{cov}=.01 ; S E=.07 ; p=.845)$. Individual change in intergroup attitude was predicted by neither moral foundation measured at $\mathrm{T} 1$, nor by their interactions with campaign exposure. Change in individualizing foundations did not show a significant relationship with intergroup attitudes (T1) or with the interaction between campaign exposure and intergroup attitudes (T1). Longitudinal change in binding foundations was unrelated to intergroup attitudes (T1) but was significantly predicted by the interaction between intergroup attitudes (T1) and campaign exposure $(\beta=.17 ; b=.04 ; S E=.02 ; 95 \%$ CI $[.00, .07]$; $p=.026)$.

To probe this interaction further, we ran a simple slope analysis, and tested the strength of the relationship between intergroup attitude at $\mathrm{T} 1$ and change in binding foundations at different levels of campaign exposure (see Figure 2). This analysis showed that the relationship was significant at a very high (+2 SD: $b=.21 ; S E=.09 ; 95 \%$ CI $[.04, .37] ; p=$ $.014)$ and a high level of campaign exposure (+1 $S D: b=$ $.14 ; S E=.06 ; 95 \%$ CI $[.02, .26] ; p=.027)$, but not at a low $(-1 S D: b=-.00 ; S E=.06 ; 95 \%$ CI $[-.12, .11] ; p=$ $.976)$ or a very low level of it $(-2 S D: b=-.07 ; S E=.08$; $95 \%$ CI $[-.22, .08] ; p=.356)$. These results indicate that negative intergroup attitude toward Muslim immigrants predicts the strengthening of binding foundations in the case of those who followed the campaign relatively closely.

\section{Discussion}

In our longitudinal study, we tested the longitudinal relationship between anti-Muslim attitudes and moral foundations during the 2018 Hungarian parliamentary election campaign. We found that intergroup attitudes predicted the longitudinal change in binding foundations, but only among those who closely followed the campaign. Furthermore, we found that moral foundations did not predict the longitudinal change in intergroup attitudes. These results support former experimental (Ciuk, 2018; Eriksson et al., 2019; Walter \& Redlawsk, 2019) and longitudinal studies (Hatemi et al., 2019; Smith et al., 2017) which concluded that moral values (measured as moral foundations) are not necessarily bases of our social beliefs, but are consequences of them since people tend to reset their moral priorities to get them in line with their current motivated social beliefs. Besides supporting this idea, our study took one step further and demonstrated in a real-life political context that people rely on the available information provided by political communication when doing this moral reset. Those who had negative attitudes toward Muslim immigrants, and were exposed to the campaign messages framing Muslim immigrants' behavior as a threat to binding moral values, were motivated to enhance their own binding morality to make it coherent with their initial attitudes.

Nonetheless, the specific psychological mechanism driving this change in morality is less clear. One plausible explanation can be that this change is a sign of a self-justification process by which people tend to rationalize their beliefs with morally relevant reasons (Hatemi et al., 2019; Smith et al., 2017). Prejudiced people could strategically 


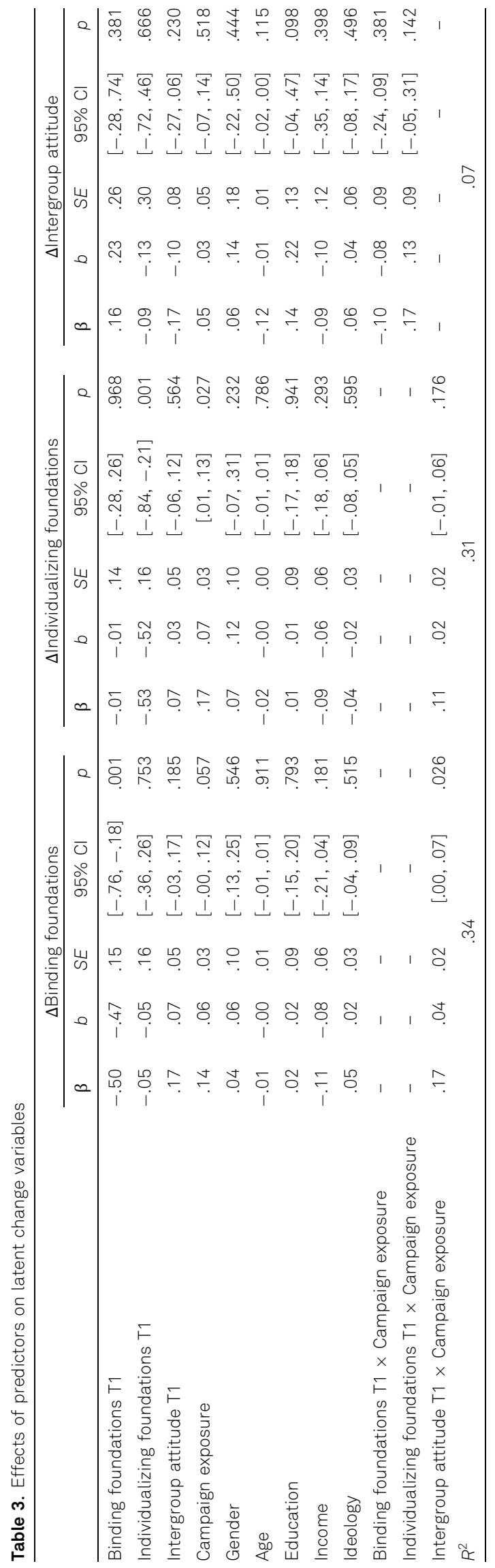




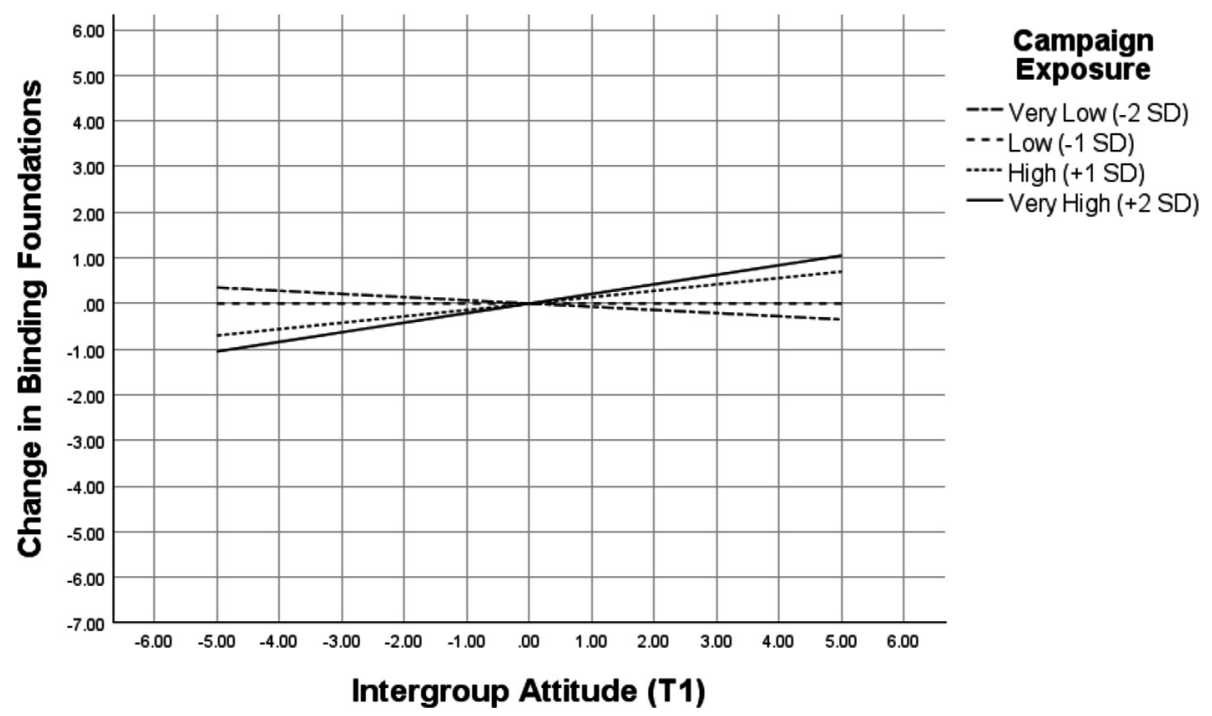

Figure 2. The relationship between intergroup attitude (T1) and change in binding foundations at different levels of campaign exposure.

apply the narrative of the Fidesz campaign to posteriorly justify their negative intergroup attitudes, which narrative strongly emphasized binding morality. According to another alternative explanation, the change in binding morality might be caused by threat perception since binding moral aspects can be effective tools to neutralize social threats by enhancing the cohesiveness of the ingroup (Van de Vyver et al., 2016; Wright \& Baril, 2013). Immigration from Muslim countries was framed as a very serious threat by the Fidesz campaign, and if prejudiced people following the camping started to perceive Muslims as threatening, then the strengthening of binding morality could be an adaptive response in their case.

We did not find evidence supporting the traditional viewpoint which considers moral foundations as actual foundations or antecedents of intergroup attitudes, nonetheless, this does not mean that this is an invalid viewpoint. Maybe our results are due to the fact that the longitudinal correlation of intergroup attitudes was relatively strong $(r=.85, p<$ .001 , see Table 2), which indicates a moderate change in these attitudes. Nevertheless, the mere fact that intergroup attitudes showed a much stronger longitudinal stability than moral foundations questions that moral foundations measured by the MFQ are stable, genetically determined traits (see also Smith et al., 2017).

Our results showed also that from the two kinds of moral foundations it was only binding morality that was related to attitudes toward Muslim immigrants but not individualizing morality. This seemingly contradicts the results of Van de Vyver and colleagues (2016) who found a significant relationship between the moral foundation of fairness and prejudice against Muslim people, and the results of Hadarics and Kende (2018a) showing a relationship between individualizing foundations and behavioral intentions toward Muslim people. Nonetheless, Van de Vyver and colleagues
(2016) did not measure fairness with the MFQ but with a non-validated single item taping into the question of intergroup equality ("There should be equality for all groups in Britain."). This can potentially bias the measurement in the context of intergroup relations, where the dependent variable is typically an intergroup belief, attitude, or behavioral intention. Furthermore, in the study of Hadarics and Kende (2018a), the outcome variables were behavioral intentions, in which case respondents did not have to consider solely the outgroup but also the behaviors themselves, where the perceived fairness and anticipated effects of these behaviors could influence the answers beyond the attitude toward Muslim people.

The lack of relationship between individualizing morality and prejudice against Muslim immigrants in our study is probably due to the nature of the Hungarian public discourse about Muslim refugees and immigration. This discourse has predominantly interpreted this issue as a question of security, and the debate was mostly about the threat posed by Middle Eastern and North African refugees (Bajomi-Lázár, 2018). Within this interpretation framework, it is likely that many people considered the well-being of Hungarians and Muslim immigrants as incompatible. Nonetheless, since individualizing moral foundations emphasize the importance of individual well-being in a universalistic manner, in such a conflictual context, it may be unclear for respondents whose well-being they should consider when answering the MFQ.

After interpreting our results, we also have to point out some limitations of our study. First of all, we have to emphasize that our hypotheses were tested only within one context involving one outgroup. Anti-Muslim prejudice within Hungary is peculiar, firstly, because the number of Muslims living in Hungary is negligible, and secondly, because besides the strong anti-Muslim and anti-immigration 
governmental campaign, there was no substantive alternative narrative about this topic and this group. Consequently, our results might not be generalizable to other countries where either real intergroup contact or available counternarratives about the nature of the given intergroup context can influence people's moral judgments. We have to emphasize also that within the literature of the moral foundations of intergroup attitudes there is an overrepresentation of outgroups like sexual or ethnic minorities, that are typically evaluated by conservatives. Our research strengthens this tendency further. Nevertheless, we know much less about the longitudinal interplay between moral foundations and outgroups that are disliked by leftists and liberals, like farright extremists or big companies. Future research should investigate these intergroup contexts to gain a clearer and ideologically more impartial picture of the complex interplay between morality and prejudice.

The political affiliation could influence our results in another way too. In our research, we only considered exposure to the anti-Muslim campaign, but not its source, which was the Fidesz. It is possible that supporters of other parties, even prejudiced ones, resisted anti-Muslim messages purely based on their source, a party they oppose. In such a case, campaign framing cannot lead to a specific moral shift, because the frame itself is refused due to its communicator. Future research should test also the role of the communicator and political affiliation in such a moral shift.

Finally, we have to note that we tested only changes in individualizing and binding foundations, but could not investigate more specific foundations, since the factorial structure of the original MFQ 30 (Graham et al., 2011) seems to be invalid within the Hungarian context (Hadarics $\&$ Kende, 2017). Nonetheless, we cannot rule out that any change in the investigated foundations is driven by one or more of the more specific foundations we could not measure in a valid manner.

\section{Conclusion}

According to the MFT, moral foundations are evolutionarily designed, biologically based trait-like characteristics that determine our moral intuitions, and as such, serve as bases for more specific beliefs. Along with other researchers (Hatemi et al., 2019; Smith et al., 2017), our results question this interpretation and the assumption that there are simple unidirectional relationships between moral concerns and more specific politically relevant beliefs. It seems that abstract moral principles can serve also as consequences of more specific attitudes and beliefs, and as we found supporting evidence, this is true also in the realm of intergroup relations. When moral values are consequences rather than antecedents of more specific beliefs, they might be products of a motivated moralization process, which process is easily facilitated by political communication.

The Hungarian governing party, Fidesz, efficiently utilized this facilitation process in its parliamentary election campaign. By framing the issue of the Refugee Crisis as a severe source of danger to the cohesion and well-being of the Hungarian society, and by emphasizing the aspects and elements of binding morality meanwhile, they were able to provide prejudiced voters with an effective tool to moralize their prejudice.

\section{Electronic Supplementary Material}

The electronic supplementary material is available with the online version of the article at https://doi.org/ 10.1027/1864-9335/a000447

ESM 1. Tables/MPlus code for the full latent change model and simple slope analysis/Original Hungarian items

ESM 2. Research data

\section{References}

Bajomi-Lázár, P. (2018). Media practices related to migration and intra-EU mobility in the EU-10 Member States. REMINDER Working Paper. https://www.reminder-project.eu/wp-content/ uploads/2018/05/with-cover_D11.2.pdf

Bajomi-Lázár, P. (2019). An anti-migration campaign and its impact on public opinion: The Hungarian case. European Journal of Communication, 34, 619-628. https://doi.org/ 10.1177/0267323119886152

Baldner, C., \& Pierro, A. (2019). Motivated prejudice: The effect of need for closure on anti-immigrant attitudes in the United States and Italy and the mediating role of binding moral foundations. International Journal of Intercultural Relations, 70 , 53-66. https://doi.org/10.1111/jasp.12620

Barnett, M. D., Öz, H. C. M., \& Marsden, A. D. (2018). Economic and social political ideology and homophobia: The mediating role of binding and individualizing moral foundations. Archives of Sexual Behavior, 47(4), 1183-1194. https://doi.org/10.1007/ s10508-017-0989-2

Bátorfy, A. (2017). Az állam foglyul ejtésétôl a piac fogvatartásáig. Orbán Viktor és a kormány media modellje 2014 után [From state capture to market capture. Viktor Orbán's and the government's media model after 2014]. Médiakutató, 18, 7-30.

Bernáth, G., \& Messing, V. (2015). Bedarálva: A menekültekkel kapcsolatos kormányzati kampány és a tôle független megszólalás terepei [Grinded: Governmental campaign about refugees and the areas of independent comments]. Médiakutató, 16, 7-17.

Bíró-Nagy, A. (2018). Politikai lottóötös: a migráció jelentôsége a magyar politikában, 2014-2018 [The winning lottery ticket of politics: the significance of migration in Hungarian politics, 20142018]. In B. Böcskei \& A. Szabó (Eds.), Várakozások és valóságok: Parlamenti választás 2018 (pp. 269-291). Napvilág Kiadó. 
Ciuk, D. J. (2018). Assessing the contextual stability of moral foundations: Evidence from a survey experiment. Research \& Politics, 5(2), 1-9. https://doi.org/10.1177/2053168018781748

Ellemers, N. (2017). Morality and the regulation of social behavior: Groups as moral anchors. Routledge.

Eriksson, K., Simpson, B., \& Strimling, P. (2019). Political double standards in reliance on moral foundations. Judgment and Decision Making, 14(4), 440-454.

Eurobarometer. (2015). Special Eurobarometer 437: Discrimination in the EU in 2015. European Union. https://doi.org/10.2838/499763

Forsberg, E., Nilsson, A., \& Jørgensen, Ø. (2019). Moral dichotomization at the heart of prejudice: The role of moral foundations and intolerance of ambiguity in generalized prejudice. Social Psychological and Personality Science, 10(8), 1002-1010. https://doi.org/10.1177/1948550618817347

Graham, J., Haidt, J., Koleva, S., Motyl, M., Iyer, R., Wojcik, S., \& Ditto, P. H. (2013). Moral foundations theory: The pragmatic validity of moral pluralism. Advances in Experimental Social Psychology, 47, 55-130. https://doi.org/10.1016/B978-0-12407236-7.00002-4

Graham, J., Haidt, J., Motyl, M., Meindl, P., Iskiwitch, C., \& Mooijman, M. (2018). Moral foundations theory: On the advantages of moral pluralism over moral monism. In K. Gray \& J. Graham (Eds.), Atlas of moral psychology (pp. 211-222). Guilford Press.

Graham, J., Nosek, B. A., Haidt, J., lyer, R., Koleva, S., \& Ditto, P. H. (2011). Mapping the moral domain. Journal of Personality and Social Psychology, 101(2), 366-385. https://doi.org/10.1037/ a0021847

Hadarics, M., \& Kende, A. (2017). A closer look at intergroup threat within the dual process model framework: The mediating role of moral foundations. Psychological Thought, 10, 167-177. https://doi.org/10.23668/psycharchives.1858

Hadarics, M., \& Kende, A. (2018a). Moral foundations of positive and negative intergroup behavior: Moral exclusion fills the gap. International Journal of Intercultural Relations, 64, 67-76. https://doi.org/10.1016/j.ijintrel.2018.03.006

Hadarics, M., \& Kende, A. (2018b). The dimensions of generalized prejudice within the dual process model: The mediating role of moral foundations. Current Psychology, 37, 731-739. https:// doi.org/10.1007/s12144-016-9544-x

Haidt, J. (2012). The righteous mind: Why good people are divided by politics and religion. Pantheon.

Haidt, J., Graham, J., \& Joseph, C. (2009). Above and below leftright: Ideological narratives and moral foundations. Psychological Inquiry, 20, 110-119. https://doi.org/10.1080/ 10478400903028573

Haidt, J., \& Joseph, C. (2004). Intuitive ethics: How innately prepared intuitions generate culturally variable virtues. Daedalus, 133(4), 55-66. https://doi.org/10.1162/0011526042365555

Halevy, N., Kreps, T. A., Weisel, O., \& Goldenberg, A. (2015). Morality in intergroup conflict. Current Opinion in Psychology, 6, 10-14. https://doi.org/10.1016/j.copsyc.2015.03.006

Hatemi, P. K., Crabtree, C., \& Smith, K. B. (2019). Ideology justifies morality: Political beliefs predict moral foundations. American Journal of Political Science, 63(4), 788-806. https://doi.org/ 10.1111/ajps.12448

Kende, A., \& Krekó, P. (2020). Xenophobia, prejudice, and rightwing populism in East-Central Europe. Current Opinion in Behavioral Sciences, 34, 29-33. https://doi.org/10.1016/ j.cobeha.2019.11.011

Kugler, M., Jost, J. T., \& Noorbaloochi, S. (2014). Another look at moral foundations theory: Do authoritarianism and social dominance orientation explain liberal-conservative differences in moral intuitions? Social Justice Research, 27, 413-431. https://doi.org/10.1007/s11211-014-0223-5
Low, M., \& Wui, M. G. L. (2016). Moral foundations and attitudes towards the poor. Current Psychology, 35, 650-656. https://doi. org/10.1007/s12144-015-9333-y

McArdle, J. J. (2009). Latent variable modeling of differences and changes with longitudinal data. Annual Review of Psychology, 60, 577-605. https://doi.org/10.1146/annurev.psych.60.110707. 163612

McDonald, R. P. (1989). An index of goodness-of-fit based on noncentrality. Journal of Classification, 6, 97-103.

Mérték Media Monitor. (2019). Mindent beborít a Fidesz-közeli média [The Fidesz-friendly media overwhelms everything]. https://mertek.atlatszo.hu/mindent-beborit-a-fidesz-kozelimedia/

Monroe, A. E., \& Plant, E. A. (2019). The dark side of morality: Prioritizing sanctity over care motivates denial of mind and prejudice toward sexual outgroups. Journal of Experimental Psychology: General, 148(2), 342-360. https://doi.org/10.1037/ xge0000537

Muthén, L. K., \& Muthén, B. O. (1998-2017). Mplus user's guide (8th ed.). Muthén \& Muthén.

Newsom, J. T. (2015). Longitudinal structural equation modeling: A comprehensive introduction. Routledge.

Nilsson, A., Erlandsson, A., \& Västfjäll, D. (2016). The congruency between moral foundations and intentions to donate, selfreported donations, and actual donations to charity. Journal of Research in Personality, 65, 22-29. https://doi.org/10.1016/j. jrp.2016.07.001

Nilsson, A., Erlandsson, A., \& Västfjäll, D. (2020). Moral foundations theory and the psychology of charitable giving. European Journal of Personality, 34, 431-447. https://doi.org/10.1002/ per.2256

Orbán, V. (2018). "State of the Nation" address. https://www. kormany.hu/en/the-prime-minister/the-prime-minister-sspeeches/viktor-orban-s-state-of-the-nation-address

Semetko, H. A. (2007). Political communication. In R. J. Dalton \& H.-D. Klingemann (Eds.), The Oxford handbook of political behaviour (pp. 123-143). Oxford University Press.

Smith, K. B., Alford, J. R., Hibbing, J. R., Martin, N. G., \& Hatemi, P. K. (2017). Intuitive ethics and political orientations: Testing moral foundations as a theory of political ideology. American Journal of Political Science, 61(2), 424-437. https://doi.org/ 10.1111/ajps.12255

Smith, I. H., Aquino, K., Koleva, S., \& Graham, J. (2014). The moral ties that bind... even to out-groups: The interactive effect of moral identity and the binding moral foundations. Psychological Science, 25(8), 1554-1562. https://doi.org/10.1177/ 0956797614534450

Tóth, T., Kékesdi-Boldog, D., Bokor, T., \& Veczán, Z. (2019). "Protect our homeland!" Populist communication in the 2018 Hungarian election campaign on Facebook. Central European Journal of Communication, 12(2), 169-186. https://doi.org/ 10.19195/1899-5101.12.2(23).4

Valentino, N., \& Nardis, Y. (2013). Political communication: Form and consequence of the information environment. In L. Huddy, D. Sears, \& J. Levy (Eds.), The Oxford handbook of political psychology (2nd ed., pp. 559-590). Oxford University Press.

Van de Vyver, J., Houston, D. M., Abrams, D., \& Vasiljevic, M. (2016). Boosting belligerence: How the July 7, 2005, London bombings affected liberals' moral foundations and prejudice. Psychological Science, 27(2), 169-177. https://doi.org/10.1177/ 0956797615615584

Voelkel, J. G., \& Brandt, M. J. (2019). The effect of ideological identification on the endorsement of moral values depends on the target group. Personality and Social Psychology Bulletin, 45(6), 851-863. https://doi.org/10.1177/0146167218798822 
Walter, A. S., \& Redlawsk, D. P. (2019). Voters' partisan responses to politicians' immoral behavior. Political Psychology, 40(5), 1075-1097. https://doi.org/10.1111/pops.12582

Waytz, A., \& Young, L. (2018). Morality for us versus them. In K. Gray \& J. Graham (Eds.), Atlas of moral psychology (pp. 186192). Guilford Press.

Wright, J. C., \& Baril, G. L. (2013). Understanding the role of dispositional and situational threat sensitivity in our moral judgments. Journal of Moral Education, 42(3), 383-397. https:// doi.org/10.1080/03057240.2013.820659

\section{History}

Received February 26, 2020

Revision received January 6, 2021

Accepted January 25, 2021

Published online May 31, 2021

\section{Authorship}

All authors were involved in all parts of the research.

\section{Funding}

The study was funded by the National Research, Development and Innovation Office (Grant No.: NKFI-K119433).

\section{ORCID}

Márton Hadarics

(iD https://orcid.org/0000-0001-8203-448X

\section{Márton Hadarics}

Department of Social Psychology

ELTE Eötvös Loránd University

Izabella utca 46

1064 Budapest

Hungary

marton.hadarics@ppk.elte.hu 